\title{
Darapladib for Preventing Ischemic Events in Stable Coronary Heart Disease
}

\author{
The STABILITY Investigators*
}

A BSTRACT

The authors and their affiliations are listed in the Appendix. Address reprint requests to Dr. Harvey D. White at Green Lane Cardiovascular Service, Auckland City Hospital, Private Bag 92024, Victoria St. W., Auckland 1142, New Zealand, or at harveyw@adhb.govt.nz.

*The investigators in the Stabilization of Atherosclerotic Plaque by Initiation of Darapladib Therapy (STABILITY) trial are listed in the Supplementary Appendix, available at NEJM.org.

This article was published on March 30, 2014, and updated on May 1, 2014, at NEJM.org.

N EngIJ Med 2014;370:1702-11.

DOI: 10.1056/NEJMoal315878

Copyright (c) 2014 Massachusetts Medical Society.

\section{BACKGROUND}

Elevated lipoprotein-associated phospholipase $\mathrm{A}_{2}$ activity promotes the development of vulnerable atherosclerotic plaques, and elevated plasma levels of this enzyme are associated with an increased risk of coronary events. Darapladib is a selective oral inhibitor of lipoprotein-associated phospholipase $A_{2}$.

\section{METHODS}

In a double-blind trial, we randomly assigned 15,828 patients with stable coronary heart disease to receive either once-daily darapladib (at a dose of $160 \mathrm{mg}$ ) or placebo. The primary end point was a composite of cardiovascular death, myocardial infarction, or stroke. Secondary end points included the components of the primary end point as well as major coronary events (death from coronary heart disease, myocardial infarction, or urgent coronary revascularization for myocardial ischemia) and total coronary events (death from coronary heart disease, myocardial infarction, hospitalization for unstable angina, or any coronary revascularization).

\section{RESULTS}

During a median follow-up period of 3.7 years, the primary end point occurred in 769 of 7924 patients (9.7\%) in the darapladib group and 819 of 7904 patients (10.4\%) in the placebo group (hazard ratio in the darapladib group, $0.94 ; 95 \%$ confidence interval $[\mathrm{CI}], 0.85$ to $1.03 ; \mathrm{P}=0.20$ ). There were also no significant between-group differences in the rates of the individual components of the primary end point or in all-cause mortality. Darapladib, as compared with placebo, reduced the rate of major coronary events ( $9.3 \%$ vs. $10.3 \%$; hazard ratio, $0.90 ; 95 \% \mathrm{CI}, 0.82$ to $1.00 ; \mathrm{P}=0.045$ ) and total coronary events ( $14.6 \%$ vs. $16.1 \%$; hazard ratio, $0.91 ; 95 \% \mathrm{CI}, 0.84$ to 0.98 ; $\mathrm{P}=0.02)$.

\section{CONCLUSIONS}

In patients with stable coronary heart disease, darapladib did not significantly reduce the risk of the primary composite end point of cardiovascular death, myocardial infarction, or stroke. (Funded by GlaxoSmithKline; STABILITY ClinicalTrials.gov number, NCT00799903.) 
THEROSCLEROTIC LESIONS IN HUMANS - in particular, vulnerable ${ }^{1}$ and ruptured plaques - are characterized by inflammatory activity and a high expression of lipoproteinassociated phospholipase $\mathrm{A}_{2} \cdot{ }^{2,3}$ In atherosclerotic plaques, lipoprotein-associated phospholipase $\mathrm{A}_{2}$ increases the production of proinflammatory and proapoptotic mediators. ${ }^{4-8}$ In a meta-analysis of individual records from 79,036 participants in 32 prospective studies, there was a continuous association between lipoprotein-associated phospholipase $\mathrm{A}_{2}$ activity and the risk of coronary heart disease, with a relative increase in risk of 1.10 ( $95 \%$ confidence interval [CI], 1.05 to 1.16) for each 1-SD increase in lipoprotein-associated phospholipase $\mathrm{A}_{2}$ activity, after adjustment for conventional risk factors. ${ }^{9}$

Darapladib is a potent and reversible oral inhibitor of lipoprotein-associated phospholipase $\mathrm{A}_{2} \cdot{ }^{10}$ In a swine model of atherosclerosis, darapladib reduced levels of lipoprotein-associated phospholipase $\mathrm{A}_{2}$ in plaque, reduced the necrotic core area, and inhibited the development of lesions in coronary arteries. ${ }^{11}$ Darapladib has also been shown to reduce lipoprotein-associated phospholipase $\mathrm{A}_{2}$ activity in human carotid plaque. ${ }^{12}$ In the Integrated Biomarker and Imaging Study 2 (IBIS-2) involving patients with coronary heart disease, darapladib, as compared with placebo, halted the progression in the volume of the necrotic core of coronary-artery plaques (a secondary end point), as determined by intravascular ultrasonographic virtual histologic analysis during a 12-month period. ${ }^{13}$ These findings suggest that darapladib could reduce the risk of events associated with coronary heart disease by altering the composition of atherosclerotic plaques to a less vulnerable state. ${ }^{1}$ In the Stabilization of Atherosclerotic Plaque by Initiation of Darapladib Therapy (STABILITY) trial, we evaluated the clinical efficacy and safety of darapladib in patients with chronic coronary heart disease.

\section{METHODS}

\section{STUDY DESIGN AND OVERSIGHT}

The study design has been described previously. ${ }^{14}$ The trial was sponsored by GlaxoSmithKline. The executive and steering committees designed the study and supervised its conduct. (A complete list of committee members is provided in the Supplementary Appendix, available with the full text of this article at NEJM.org.) In each country, the study was approved by national regulatory authorities and by local ethics committees or institutional review boards, according to local regulations.

Data were collected and managed by GlaxoSmithKline. Unblinded interim analyses of the ongoing trial, including four efficacy analyses (two prespecified and two unplanned) and semiannual safety analyses, were conducted at the University of Wisconsin-Madison and reviewed by an independent data and safety monitoring committee. The final analyses of trial data were performed by GlaxoSmithKline. Final statistical analyses of key efficacy and safety measures, including those presented in this article, were independently verified by the Duke Clinical Research Institute.

The first draft of the manuscript was written by the first author. The executive and steering committees contributed to subsequent drafts of the manuscript and approved the submission of the final manuscript for publication. The study's cochairs had full access to all data, verified their accuracy, and vouch for the fidelity of the study to the protocol, available at NEJM.org.

\section{STUDY POPULATION}

Patients were eligible to participate in the study if they had coronary heart disease, as documented by at least one of the following: previous myocardial infarction, previous percutaneous coronary intervention (PCI) or coronary-artery bypass grafting $(\mathrm{CABG})$, or multivessel coronary artery disease. In addition, at least one of the following additional predictors of cardiovascular risk was required: an age of 60 years or older, diabetes requiring pharmacotherapy, a high-density lipoprotein (HDL) cholesterol level of less than $40 \mathrm{mg}$ per deciliter (1.03 mmol per liter), status as a smoker of five or more cigarettes per day at study entry or within 3 months before screening, moderate renal dysfunction, or polyvascular arterial disease. Exclusion criteria were planned PCI or CABG or another major surgical procedure, current liver disease, severe renal impairment, a history of nephrectomy or kidney transplantation, current New York Heart Association class III or IV heart failure, or severe asthma that was poorly controlled with standard medical therapy. Details of the inclusion and exclusion criteria are provided in the Supplementary Appendix. All patients provided written informed consent. 
STUDY PROCEDURES AND FOLLOW-UP

After baseline assessments were performed, patients were randomly assigned, with the use of an interactive voice-response system, to receive either a once-daily oral dose of darapladib $(160 \mathrm{mg}$ ) or matching placebo to be taken with food and swallowed whole. The assigned dose of darapladib was expected to lower plasma levels of lipoprotein-associated phospholipase $\mathrm{A}_{2}$ by approximately $60 \% .{ }^{13}$

Patients were instructed to return for clinic visits 1,3 , and 6 months after randomization and thereafter every 6 months for the duration of the study. In addition, patients were followed up by telephone beginning at 9 months and then every 6 months thereafter until the end of the study.

Investigators were strongly encouraged to treat patients according to international guidelines for secondary prevention of coronary heart disease. All patients were to receive long-term treatment with platelet-inhibitor therapy and statin therapy unless such therapy was not indicated according to guidelines, was contraindicated, or resulted in unacceptable side effects. Metrics of standard of care were monitored by the study leaders and provided to all investigators every 6 months, which allowed the investigators to compare the standard of care at their sites with national and international standards at other sites participating in this study. In addition, the importance of adherence to standard-of-care medications was reinforced over the duration of the trial and at periodic meetings with investigators.

Patients were instructed to continue taking the study drug until the day before their end-oftreatment visit. Patients who permanently discontinued a study drug before the end of the study were contacted by telephone for an assessment of clinical outcomes. At the end of the study, all patients were asked to return to the clinic within a 3-month period for their final study visit. Final survival status was sought for patients who were lost to follow-up or withdrew consent.

\section{STUDY END POINTS}

The primary end point was a composite of cardiovascular death, myocardial infarction, or stroke. Secondary end points included major coronary events (a composite of death from coronary heart disease, myocardial infarction, or urgent coronary revascularization for myocardial ischemia); total coronary events (a composite of death from coronary heart disease, myocardial infarction, hospitalization for unstable angina, or any coronary revascularization procedure); the individual components of the primary end point; a composite of all-cause mortality, myocardial infarction, or stroke; and all-cause mortality. Definitions of the primary and secondary end points are provided in the Supplementary Appendix.

\section{LABORATORY TESTING}

All laboratory tests were performed at central laboratories (Quest Diagnostics Clinical Laboratories). The estimated glomerular filtration rate (GFR) was calculated with the use of the Modification of Diet in Renal Disease method. ${ }^{15}$

\section{SAFETY MONITORING AND ADJUDICATION}

Investigators were responsible for detecting, documenting, and reporting adverse events and serious adverse events. Information on adverse events was collected from the time the randomized regimens were started until 35 days after the last dose of a study drug was taken or at the next follow-up visit, whichever occurred later. Serious adverse events that were assessed as being related to a study drug or related to study participation were recorded up to and including any follow-up contact. The occurrence of cancers and of gastrointestinal polyps or neoplasms was recorded until the end of the study, including during the period after discontinuation of the study drug, since 2-year carcinogenicity studies in rodents had suggested that darapladib was associated with the development of jejunal adenomas or adenocarcinomas in male mice and rats. Other adverse events of special interest included asthma, anaphylaxis, diarrhea, and odor-related events, because in previous studies, ${ }^{13}$ darapladib had been associated with an unpleasant odor of skin, urine, or feces.

Suspected primary and secondary end points were evaluated by an independent clinical-events committee whose members were unaware of the study-group assignments. Gastrointestinal neoplasms and cancers were adjudicated by a separate committee in a blinded fashion.

\section{STATISTICAL ANALYSIS}

We anticipated an annual event rate for the primary end point of $4 \%$ in the placebo group. We then estimated that 1500 events would be required for the study to have a power of $90 \%$ to 
detect a relative-risk reduction of $15.5 \%$ in the rate of the primary end point in the darapladib group, as compared with the placebo group.

All patients who underwent randomization were included in the intention-to-treat analyses. Time-to-event analyses were performed with the use of Kaplan-Meier estimates for the primary and secondary end points. Hazard ratios and 95\% confidence intervals were estimated with the use of Cox proportional-hazards models. The effect of treatment on the primary end point was estimated with the use of hazard ratios and adjusted $95.1 \%$ confidence intervals, with a two-sided $\mathrm{P}$ value of 0.049 indicating statistical significance after adjustment for the four interim analyses conducted by the data and safety monitoring committee. For secondary and other end points, no adjustments were made for multiple testing. Nominal significance refers to an unadjusted $P$ value of less than 0.05 in which the type I error was not controlled at the $5 \%$ level.

The consistency of effects on efficacy end points was prespecified to be explored in 35 subgroups, without adjustment for multiple comparisons. The analyses of safety data focused on adverse events, laboratory data, and vital signs and included all patients who received at least one dose of a study drug. Baseline and ontreatment lipoprotein-associated phospholipase $\mathrm{A}_{2}$ levels are not yet available and thus are not reported here.

\section{RESULTS}

\section{STUDY PATIENTS}

From December 2008 through April 2010, we enrolled 15,828 patients at 663 centers in 39 countries (Fig. 1). A total of 7924 patients were randomly assigned to the darapladib group, and 7904 were assigned to the placebo group. The median age of the patients was 65 years; $81 \%$ were men, $78 \%$ were white, $20 \%$ were current or recent smokers, and 34\% had diabetes mellitus requiring pharmacotherapy (Table 1 , and Table S1 in the Supplementary Appendix). The median lowdensity lipoprotein (LDL) cholesterol level at baseline was $79.9 \mathrm{mg}$ per deciliter (2.07 $\mathrm{mmol}$ per liter).

\section{FOLLOW-UP, ADHERENCE, AND BACKGROUND THERAPY}

The median duration of follow-up for the primary end point was 3.7 years (interquartile range,
3.5 to 3.8). The median duration of study-drug exposure was 3.5 years in the darapladib group and 3.6 years in the placebo group. We were able to ascertain vital status for $99.3 \%$ of the patients $(15,722$ of 15,828$)$ and for $99.6 \%$ of the total possible follow-up time. For the analysis of the primary end point, complete follow-up was obtained in $96.5 \%$ of patients and for $97.7 \%$ of total followup time (Fig. S1 in the Supplementary Appendix). The percentage of patients with at least $80 \%$ adherence to treatment, as determined on the basis of pill counts, was $89.3 \%$ in the darapladib group and $91.3 \%$ in the placebo group.

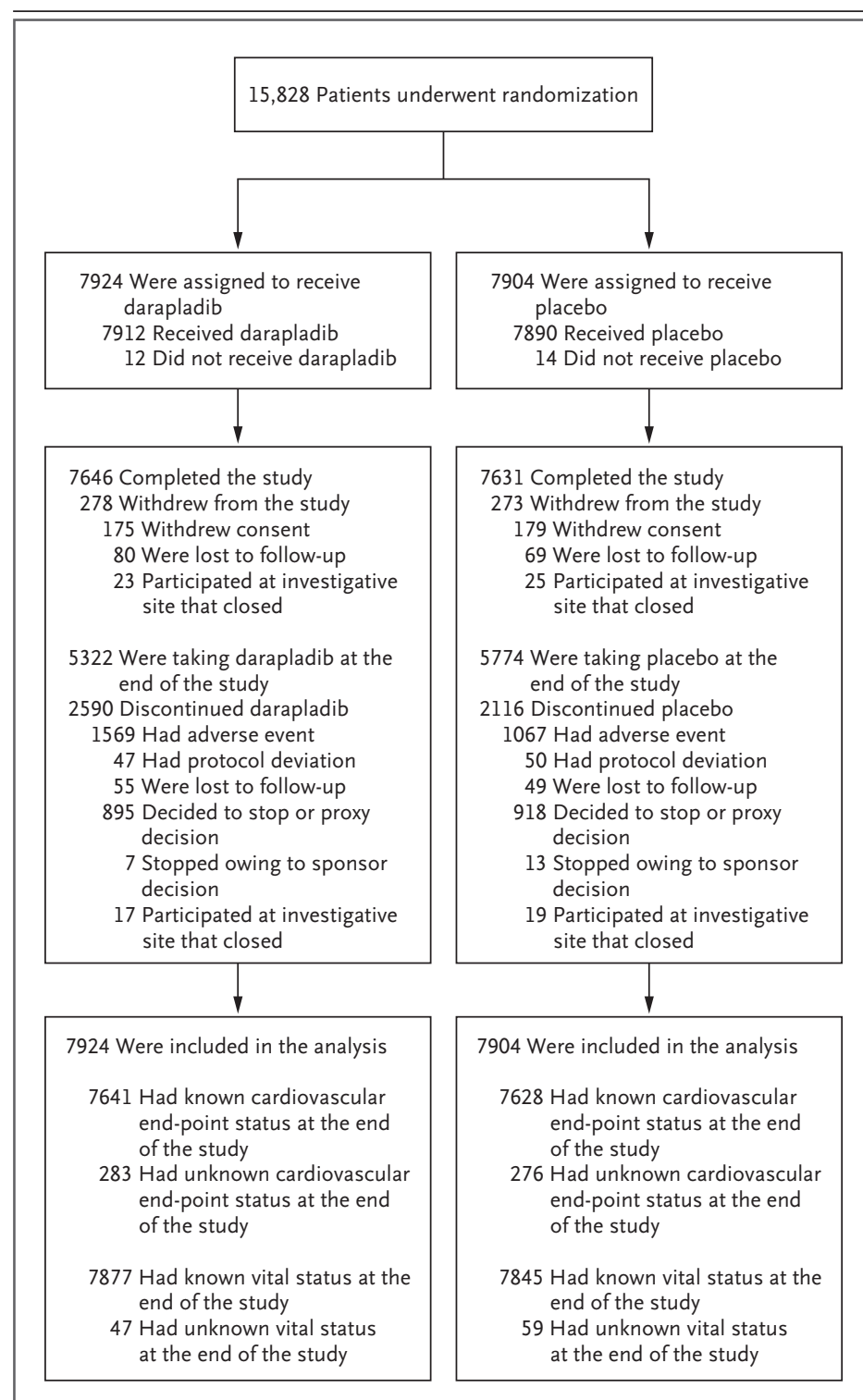

Figure 1. Randomization and Follow-up. 


\begin{tabular}{|c|c|c|}
\hline Characteristic & Placebo ( $N=7904)$ & Darapladib $(\mathrm{N}=7924)$ \\
\hline \multicolumn{3}{|l|}{ Age } \\
\hline Median (IQR) - yr & $65.0(59.0-71.0)$ & $65.0(59.0-71.0)$ \\
\hline$<65 \mathrm{yr}-$ no. $(\%)$ & $3893(49.3)$ & $3808(48.1)$ \\
\hline $65-74$ yr - no. (\%) & $2938(37.2)$ & $3022(38.1)$ \\
\hline$\geq 75 \mathrm{yr}-$ no. (\%) & $1073(13.6)$ & $1094(13.8)$ \\
\hline Female sex — no. (\%) & $1506(19.1)$ & $1461(18.4)$ \\
\hline \multicolumn{3}{|l|}{ Race or ethnic group — no. (\%) $\dagger$} \\
\hline White & $6174(78.1)$ & $6232(78.6)$ \\
\hline Black & $191(2.4)$ & $175(2.2)$ \\
\hline Central, South, or Southeast Asian & $598(7.6)$ & $592(7.5)$ \\
\hline East Asian or Japanese & $766(9.7)$ & $758(9.6)$ \\
\hline Other & $175(2.2)$ & $167(2.1)$ \\
\hline \multicolumn{3}{|l|}{ Region of enrollment - no. (\%) } \\
\hline \multicolumn{3}{|l|}{ North America } \\
\hline All & $2016(25.5)$ & $2007(25.3)$ \\
\hline United States & $1555(19.7)$ & $1547(19.5)$ \\
\hline South America & $597(7.6)$ & $602(7.6)$ \\
\hline Western Europe & $1980(25.1)$ & $2006(25.3)$ \\
\hline Eastern Europe & $1764(22.3)$ & $1767(22.3)$ \\
\hline Asia or Pacific Rim & $1547(19.6)$ & $1542(19.5)$ \\
\hline \multicolumn{3}{|l|}{ Cardiovascular risk factors } \\
\hline Diabetes requiring pharmacotherapy — no. (\%) & $2687(34.0)$ & $2664(33.6)$ \\
\hline \multicolumn{3}{|l|}{ High-density lipoprotein cholesterol } \\
\hline Median (IQR) - mg/dl & $44.4(38.6-52.9)$ & $44.8(38.6-53.7)$ \\
\hline$<40 \mathrm{mg} / \mathrm{dl}-$ no. (\%) & $2786(35.2)$ & $2646(33.4)$ \\
\hline Smoker - no. $(\%) \ddagger$ & $1656(21.0)$ & $1572(19.8)$ \\
\hline Renal dysfunction - no. (\%)』 & $2374(30.0)$ & $2410(30.4)$ \\
\hline Polyvascular disease - no. (\%) & $1187(15.0)$ & $1185(15.0)$ \\
\hline \multicolumn{3}{|l|}{ Qualifying diagnosis of coronary heart disease — no. (\%) } \\
\hline Previous myocardial infarction & $4642(58.7)$ & $4681(59.1)$ \\
\hline Previous coronary revascularization & $5911(74.8)$ & $5952(75.1)$ \\
\hline Percutaneous coronary intervention & $3978(50.3)$ & $3987(50.3)$ \\
\hline Coronary-artery bypass grafting & $2592(32.8)$ & $2644(33.4)$ \\
\hline Multivessel disease & $1191(15.1)$ & $1199(15.1)$ \\
\hline
\end{tabular}

* There was no significant difference between the two groups, except among patients who had a high-density lipoprotein cholesterol level of less than $40 \mathrm{mg}$ per deciliter $(\mathrm{P}=0.01)$. Percentages may not total 100 because of rounding. To convert the values for cholesterol to millimoles per liter, multiply by 0.02586 . IQR denotes interquartile range.

$\uparrow$ Race or ethnic group was self-reported.

$\uparrow$ Smokers included both current smokers of five or more cigarettes per day and those who were smokers within 3 months before screening.

$\int$ Renal dysfunction was defined as an estimated glomerular filtration rate of 30 to $59 \mathrm{ml}$ per minute per $1.73 \mathrm{~m}^{2}$ of bodysurface area (moderate kidney disease) or a urine albumin-to-creatinine ratio of 30 or more (as measured in milligrams of albumin and grams of creatinine).

The use of guideline-recommended treatments for secondary prevention was high. At trial closeout, $90 \%$ of the patients were taking aspirin, $96 \%$ statins, $79 \%$ beta-blockers, $54 \%$ angiotensin- converting-enzyme inhibitors, and $26 \%$ angiotensin II-receptor blockers. The median LDL cholesterol level at the end of the study was $78.0 \mathrm{mg}$ per deciliter (2.02 mmol per liter) in the darap- 
ladib group and $78.8 \mathrm{mg}$ per deciliter $(2.04 \mathrm{mmol}$ per liter) in the placebo group. The mean blood pressure at the end of the study was $132 / 77 \mathrm{~mm} \mathrm{Hg}$ in the darapladib group and $131 / 77 \mathrm{~mm} \mathrm{Hg}$ in the placebo group.

\section{EFFICACY OUTCOMES}

\section{Primary End Point}

The primary end point occurred in 769 of 7924 patients $(9.7 \%)$ in the darapladib group and in 819 of 7904 patients (10.4\%) in the placebo group (hazard ratio in the darapladib group, 0.94; 95\% CI, 0.85 to $1.03 ; \mathrm{P}=0.20$ ) (Table 2 and Fig. 2).
There were no significant effects of darapladib on any of the components of the primary end point (cardiovascular death, myocardial infarction, or stroke) or on all-cause mortality. The hazard ratio for the effect of darapladib on myocardial infarction was 0.89 (95\% CI, 0.77 to 1.03; $\mathrm{P}=0.11$ ). The effects on different types of myocardial infarction are shown in the Table S2 in the Supplementary Appendix.

The treatment effect with respect to the primary end point was consistent in almost all prespecified subgroups. The only interactions below the $\mathrm{P}=0.10$ level were among smokers $(\mathrm{P}=0.04$

\begin{tabular}{|c|c|c|c|c|c|c|}
\hline \multirow[t]{3}{*}{ End Point } & \multicolumn{2}{|c|}{ Placebo $(\mathrm{N}=7904)$} & \multicolumn{2}{|c|}{ Darapladib ( $N=7924)$} & \multirow[t]{3}{*}{ Hazard Ratio $(95 \% \mathrm{Cl}) \grave{\dagger}$} & \multirow[t]{3}{*}{ P Value } \\
\hline & $\begin{array}{l}\text { Patients } \\
\text { with Events }\end{array}$ & $\begin{array}{l}\text { Event } \\
\text { Rate }\end{array}$ & $\begin{array}{l}\text { Patients } \\
\text { with Events }\end{array}$ & $\begin{array}{l}\text { Event } \\
\text { Rate }\end{array}$ & & \\
\hline & no. $(\%)$ & $\begin{array}{l}\text { no. of events/ } \\
100 \text { person- } y r\end{array}$ & no. (\%) & $\begin{array}{l}\text { no. of events/ } \\
100 \text { person- } y r\end{array}$ & & \\
\hline Primary end point & $819(10.4)$ & 3.04 & $769(9.7)$ & 2.85 & $0.94(0.85-1.03)$ & 0.20 \\
\hline Cardiovascular death & $315(4.0)$ & 1.13 & $308(3.9)$ & 1.11 & & \\
\hline Nonfatal myocardial infarction & $369(4.7)$ & 1.36 & $329(4.2)$ & 1.21 & & \\
\hline Nonfatal stroke & $135(1.7)$ & 0.49 & $132(1.7)$ & 0.48 & & \\
\hline \multicolumn{7}{|l|}{ Secondary end point } \\
\hline Major coronary event & $814(10.3)$ & 3.03 & $737(9.3)$ & 2.74 & $0.90(0.82-1.00)$ & 0.045 \\
\hline Death from coronary heart disease & $303(3.8)$ & 1.09 & $284(3.6)$ & 1.02 & & \\
\hline Nonfatal myocardial infarction & $368(4.7)$ & 1.36 & $325(4.1)$ & 1.20 & & \\
\hline $\begin{array}{l}\text { Urgent coronary revascularization for } \\
\text { myocardial ischemia }\end{array}$ & $143(1.8)$ & 0.52 & $128(1.6)$ & 0.46 & & \\
\hline Total coronary events & $1269(16.1)$ & 4.90 & $1159(14.6)$ & 4.45 & $0.91(0.84-0.98)$ & 0.02 \\
\hline Death from coronary heart disease & $293(3.7)$ & 1.06 & $270(3.4)$ & 0.97 & & \\
\hline Nonfatal myocardial infarction & $320(4.0)$ & 1.18 & $281(3.5)$ & 1.03 & & \\
\hline Hospitalization for unstable angina & $145(1.8)$ & 0.53 & $129(1.6)$ & 0.47 & & \\
\hline Any coronary revascularization procedure & $511(6.5)$ & 1.91 & $479(6.0)$ & 1.78 & & \\
\hline Cardiovascular death & $373(4.7)$ & 1.34 & $359(4.5)$ & 1.29 & $0.96(0.83-1.11)$ & 0.59 \\
\hline Myocardial infarction & $405(5.1)$ & 1.49 & $361(4.6)$ & 1.33 & $0.89(0.77-1.03)$ & 0.11 \\
\hline Stroke & $152(1.9)$ & 0.55 & $154(1.9)$ & 0.56 & $1.01(0.81-1.27)$ & 0.92 \\
\hline $\begin{array}{l}\text { All-cause mortality, nonfatal myocardial } \\
\text { infarction, or nonfatal stroke }\end{array}$ & $962(12.2)$ & 3.57 & $926(11.7)$ & 3.43 & $0.96(0.88-1.05)$ & 0.40 \\
\hline All-cause mortality & $458(5.8)$ & 1.65 & $465(5.9)$ & 1.67 & & \\
\hline Nonfatal myocardial infarction & $369(4.7)$ & 1.36 & $329(4.2)$ & 1.21 & & \\
\hline Nonfatal stroke & $135(1.7)$ & 0.49 & $132(1.7)$ & 0.48 & & \\
\hline Total all-cause mortality & $577(7.3)$ & 2.00 & $582(7.3)$ & 2.02 & $1.01(0.90-1.13)$ & 0.87 \\
\hline
\end{tabular}

* The components of each of the composite end points have been summarized as mutually exclusive components without hazard ratios, confidence intervals, or $\mathrm{P}$ values. A mutually exclusive component is the first occurrence of any event in the composite. All other categories represent time-to-event end points and are specified as primary or secondary end points in the protocol.

$\uparrow$ Hazard ratios are for the darapladib group, as compared with the placebo group. 


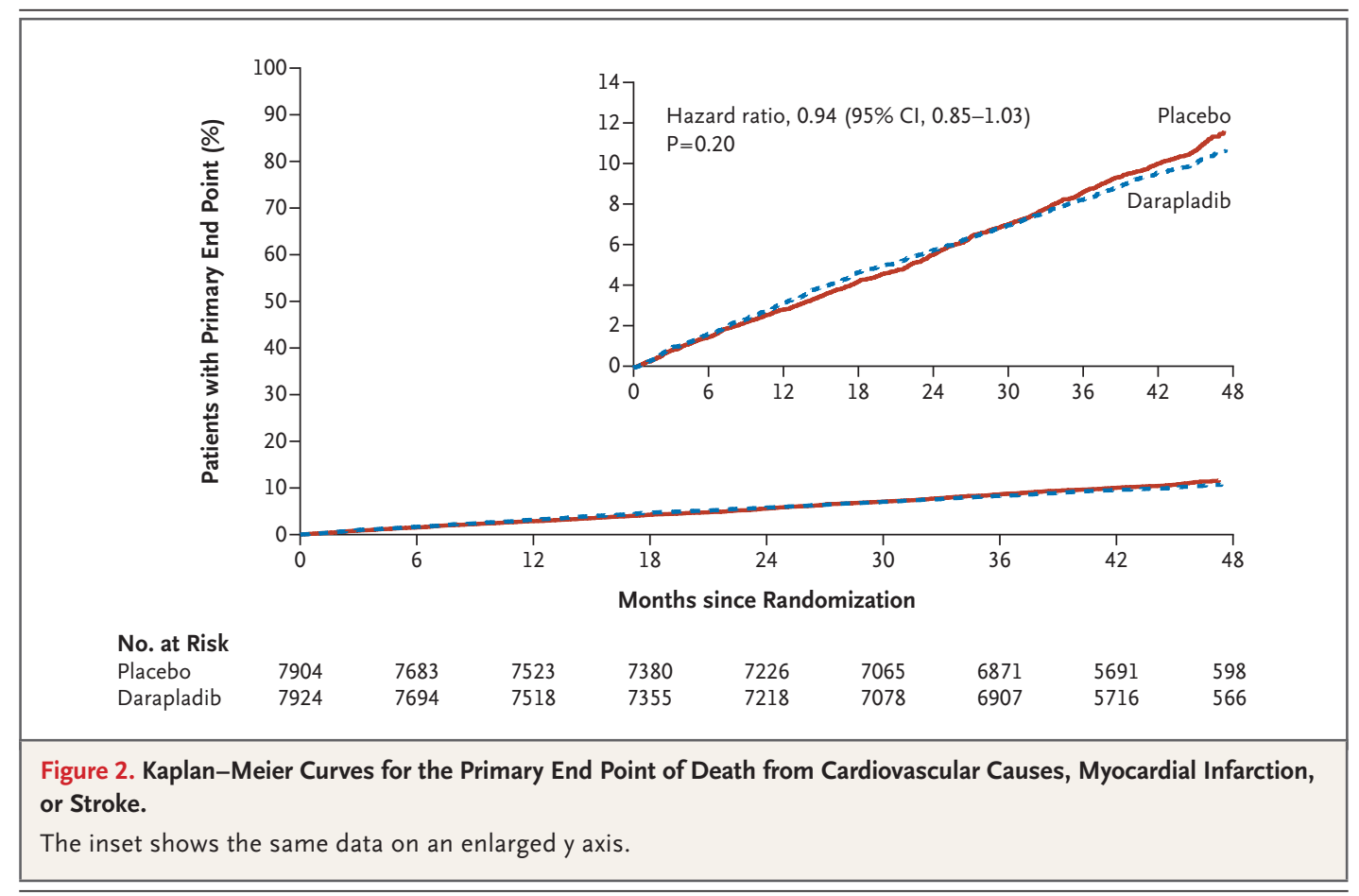

for interaction) and white patients $(\mathrm{P}=0.08$ for interaction) (Fig. S2 in the Supplementary Appendix).

\section{Secondary End Points}

Among patients receiving darapladib, there was a nominally significant reduction in the first prespecified secondary end point of a composite of major coronary events, which occurred in 737 patients $(9.3 \%)$ in the darapladib group and in 814 patients $(10.3 \%)$ in the placebo group (hazard ratio, $0.90 ; 95 \% \mathrm{CI}, 0.82$ to $1.00 ; \mathrm{P}=0.045$ ) (Table 2, and Fig. S3 in the Supplementary Appendix). Similar effects were observed for the composite of total coronary events (hazard ratio, $0.91 ; 95 \%$ CI, 0.84 to $0.98 ; \mathrm{P}=0.02$ ).

\section{ADVERSE EVENTS}

More patients in the darapladib group than in the placebo group discontinued the study drug (32.7\% vs. $26.8 \%$; hazard ratio, 1.29 ; $95 \% \mathrm{CI}$, 1.22 to 1.37 ) (Fig. $S 4$ in the Supplementary Appendix). Any adverse event leading to discontinuation of a study drug occurred in $19.8 \%$ of the patients in the darapladib group and in $13.5 \%$ of those in the placebo group (hazard ratio, 1.55; 95\% CI, 1.43 to 1.67) (Table 3). More patients in the darapladib group than in the pla- cebo group discontinued the study drug because of diarrhea (3.2\% vs. $0.8 \%$ ), feces odor ( $2.2 \%$ vs. $0.1 \%)$, urine odor ( $1.4 \%$ vs. $<0.1 \%$ ), and skin odor ( $2.2 \%$ vs. $0.1 \%)$.

There were more serious adverse events of renal failure in the darapladib group than in the placebo group (1.5\% vs. $1.1 \%$; hazard ratio, 1.35 ; $95 \%$ CI, 1.03 to 1.78). At 3 months, the mean estimated GFR was lower by $2 \mathrm{ml}$ per minute per $1.73 \mathrm{~m}^{2}$ of body-surface area in the darapladib group than in the placebo group, with a similar between-group difference observed during the entire treatment period. There was no significant between-group difference in the subgroup of 2650 patients in whom the estimated GFR was measured approximately 1 month after the end of treatment, with a change from baseline in the estimated GFR in the darapladib group, as compared with the placebo group, of $-0.12 \mathrm{ml}$ per minute per $1.73 \mathrm{~m}^{2}(95 \% \mathrm{CI},-1.35$ to 1.12 ; $\mathrm{P}=0.85$ ). No significant between-group difference in the number of overall cancers or gastrointestinal cancers was observed.

\section{DISCUSSION}

In this large, multicenter, randomized trial involving patients with stable chronic coronary heart 
disease who were followed for a median of 3.7 years, darapladib did not significantly reduce the incidence of the primary end point of cardiovascular death, myocardial infarction, or stroke. There were no significant reductions in the incidence of the components of the primary end point, as assessed individually, or in the rate of all-cause mortality. There was a nominally significant reduction in the secondary end points of major and total coronary events, which is a signal of possible efficacy. The lack of effect of the administered dose of darapladib on the primary end point may relate to a smaller effect on vulnerable coronary plaque than was anticipated on the basis of previous studies. ${ }^{12,13}$

It is possible that the coronary risk among patients in our study may already have been minimized by concurrent therapy. The trial was designed to test the incremental effect of a new treatment administered in patients who were receiving a high level of standard of care for secondary prevention at baseline. Thus, more than a third of the patients had an LDL cholesterol level of less than $70 \mathrm{mg}$ per deciliter $(1.81 \mathrm{mmol}$ per liter) at baseline, and revascularization had been performed in $75 \%$ of the patients before randomization. High rates of the use of evidencebased medications were maintained throughout the trial. These standards of care are consistently higher than those that were observed in patients with stable chronic coronary heart disease who were included in previous large international registries. ${ }^{16-18}$ These factors probably reduced event rates in the two study groups and may have reduced the proportion of events that were modifiable.

Another consideration is that $96 \%$ of the patients at trial closeout were taking statins, which have been shown to reduce levels of lipoproteinassociated phospholipase $\mathrm{A}_{2}$ by up to $35 \% .^{19-21}$ In addition, in the Long-Term Intervention with Pravastatin in Ischemic Disease (LIPID) study, among patients with stable chronic coronary heart disease, more than half the treatment effect of pravastatin in reducing rates of death from coronary heart disease or myocardial infarction was estimated to be due to an association with a reduction in levels of lipoprotein-associated phospholipase $\mathrm{A}_{2} .{ }^{22}$ Incremental benefits of inhibiting lipoprotein-associated phospholipase $\mathrm{A}_{2}$ activity, if present, could be less in patients treated with statins.

\begin{tabular}{|c|c|c|}
\hline Event & $\begin{array}{l}\text { Placebo } \\
(\mathrm{N}=7890)\end{array}$ & $\begin{array}{l}\text { Darapladib } \\
(\mathrm{N}=7912)\end{array}$ \\
\hline & \multicolumn{2}{|c|}{ no. of patients (\%) } \\
\hline Any serious adverse event* & $3448(43.7)$ & $3369(42.6)$ \\
\hline $\begin{array}{l}\text { Any adverse event leading to study-drug } \\
\text { discontinuation }\end{array}$ & $1067(13.5)$ & $1569(19.8)$ \\
\hline \multicolumn{3}{|l|}{ Diarrhea } \\
\hline Any & $495(6.3)$ & $965(12.2)$ \\
\hline Leading to study-drug discontinuation & $60(0.8)$ & $254(3.2)$ \\
\hline \multicolumn{3}{|l|}{ Abnormal feces odor } \\
\hline Any & $63(0.8)$ & $728(9.2)$ \\
\hline Leading to study-drug discontinuation & $5(0.1)$ & $177(2.2)$ \\
\hline \multicolumn{3}{|l|}{ Abnormal skin odor } \\
\hline Any & $34(0.4)$ & $383(4.8)$ \\
\hline Leading to study-drug discontinuation & $4(0.1)$ & $174(2.2)$ \\
\hline \multicolumn{3}{|l|}{ Abnormal urine odor } \\
\hline Any & $81(1.0)$ & $473(6.0)$ \\
\hline Leading to study-drug discontinuation & $1(<0.1)$ & $113(1.4)$ \\
\hline Asthma & $64(0.8)$ & $43(0.5)$ \\
\hline Renal failure $\dagger$ & $89(1.1)$ & $120(1.5)$ \\
\hline \multicolumn{3}{|l|}{ Newly diagnosed cancer } \\
\hline Any & $529(6.7)$ & $508(6.4)$ \\
\hline Adjudicated gastrointestinal & $105(1.3)$ & $102(1.3)$ \\
\hline Liver eventsł & $52(0.7)$ & $54(0.7)$ \\
\hline Anaphylaxisł & $7(0.1)$ & $9(0.1)$ \\
\hline
\end{tabular}

* Serious adverse events include cardiovascular events. A complete list of adverse events according to system organ class is provided in Table S3 in the Supplementary Appendix.

$\uparrow$ Patients listed in this category include all those with serious renal adverse events according to the Medical Dictionary for Regulatory Activities preferred terms of acute renal failure, renal failure, and chronic renal failure. The mean $( \pm S D)$ change from baseline in the estimated glomerular filtration rate at the end of the treatment period was a reduction of $0.8 \pm 14.1 \mathrm{ml}$ per minute per $1.73 \mathrm{~m}^{2}$ among 7322 patients who were evaluated in the darapladib group and an increase of $1.7 \pm 14.4 \mathrm{ml}$ per minute per $1.73 \mathrm{~m}^{2}$ among 7498 patients who were evaluated in the placebo group, for a between-group difference (darapladib group minus placebo group) of $-2.5 \mathrm{ml}$ per minute per $1.73 \mathrm{~m}^{2}$ (95\% confidence interval, -3.0 to -2.1 ).

$\Varangle$ All the patients included in this category met the criteria for discontinuing the study on the basis of these events, as specified in the protocol.

There was a nominally significant reduction of approximately $10 \%$ in the rate of the prespecified secondary composite end points of major and total coronary events. The effects on these end points were consistent across the components of these composite end points, including death from coronary heart disease, myocardial infarction, coronary revascularization, 
and hospitalization for unstable angina, and it is possible that the inhibition of lipoproteinassociated phospholipase $A_{2}$ may reduce these measures of coronary disease risk. However, these findings should be considered exploratory and of uncertain importance in light of the lack of effect on the primary end point.

In accordance with previous findings, there was an increase in the rate of diarrhea among patients receiving darapladib, as compared with those receiving placebo, along with increases in the rates of odor (in skin, feces, and urine), an effect that is thought to be related to the sulfhydryl group in the darapladib molecule. Because of the occurrence of these events, there were more study-drug discontinuations in the darapladib group than in the placebo group, with most discontinuations occurring during the first year. The mechanisms and clinical significance of the changes in renal laboratory measures and of the renal serious adverse events are uncertain.

In conclusion, we evaluated a novel mechanism for reducing plaque vulnerability by inhibition of lipoprotein-associated phospholipase $\mathrm{A}_{2}$ with darapladib in patients with stable coronary heart disease who were receiving guideline-based background medical therapy. Darapladib did not significantly reduce the rate of the primary end point of cardiovascular death, myocardial infarction, or stroke.

\section{Supported by GlaxoSmithKline.}

Disclosure forms provided by the authors are available with the full text of this article at NEJM.org.

We thank the patients who participated in the trial; Ebba Bergman, Ph.D., Uppsala Clinical Research Center (UCR), Uppsala University, Uppsala, Sweden, for scientific publications management; and Charlene Nell, Green Lane Cardiovascular Service, Auckland City Hospital, Auckland, New Zealand, for administrative assistance.

\section{APPENDIX}

The authors are as follows: Harvey D. White, D.Sc., Claes Held, M.D., Ph.D., Ralph Stewart, M.D., Elizabeth Tarka, M.D., Rebekkah Brown, Dr.PH., Richard Y. Davies, M.S., Andrzej Budaj, M.D., Ph.D., Robert A. Harrington, M.D., P. Gabriel Steg, M.D., Diego Ardissino, M.D., Paul W. Armstrong, M.D., Alvaro Avezum, M.D., Ph.D., Philip E. Aylward, B.M., B.Ch., Ph.D., Alfonso Bryce, M.D., Hong Chen, M.D., Ming-Fong Chen, M.D., Ph.D., Ramon Corbalan, M.D., Anthony J. Dalby, M.B., Ch.B., Nicolas Danchin, M.D., Ph.D., Robbert J. De Winter, M.D., Ph.D., Stefan Denchev, M.D., Ph.D., Rafael Diaz, M.D., Moses Elisaf, M.D., Ph.D., Marcus D. Flather, M.B., B.S., Assen R. Goudev, M.D., Christopher B. Granger, M.D., Liliana Grinfeld, M.D., Ph.D., Judith S. Hochman, M.D., Steen Husted, M.D., D.Sc., Hyo-Soo Kim, M.D., Ph.D., Wolfgang Koenig, M.D., Ales Linhart, M.D., Ph.D., Eva Lonn, M.D., José López-Sendón, M.D., Ph.D., Athanasios J. Manolis, M.D., Emile R. Mohler III, M.D., José C. Nicolau, M.D., Ph.D., Prem Pais, M.D., Alexander Parkhomenko, M.D., Ph.D., Terje R. Pedersen, M.D., Ph.D., Daniel Pella, M.D., Ph.D., Marco A. Ramos-Corrales, M.D., Mikhail Ruda, M.D., Mátyás Sereg, M.D., Saulat Siddique, M.D., Peter Sinnaeve, M.D., Ph.D., Peter Smith, Pharm.D., Piyamitr Sritara, M.D., Henk P. Swart, M.D., Rody G. Sy, M.D., Tamio Teramoto, M.D., Ph.D., Hung-Fat Tse, M.D., Ph.D., David Watson, M.Sc., W. Douglas Weaver, M.D., Robert Weiss, M.D., Margus Viigimaa, M.D., Ph.D., Dragos Vinereanu, M.D., Ph.D., Junren Zhu, M.D., Christopher P. Cannon, M.D., and Lars Wallentin, M.D., Ph.D., for the STABILITY Investigators.

The authors' affiliations are as follows: Green Lane Cardiovascular Service, Auckland City Hospital and University of Auckland, Auckland, New Zealand (H.D.W., R.S.); the Department of Medical Sciences, Cardiology, Uppsala University, and Uppsala Clinical Research Center, Uppsala, Sweden (C.H., L.W.); Metabolic Pathways and Cardiovascular Therapeutic Area, GlaxoSmithKline, King of Prussia, PA (E.T., R.Y.D.); Metabolic Pathways and Cardiovascular Therapeutic Area, GlaxoSmithKline, Research Triangle Park (R.B., P. Smith, D.W.), and Duke University Medical Center, Durham (C.B.G.) - both in North Carolina; Postgraduate Medical School, Grochowski Hospital, Warsaw, Poland (A. Budaj); the Department of Medicine, Stanford University, Stanford, CA (R.A.H.); INSERM Unité 1148, Assistance Publique-Hôpitaux de Paris, Département Hospitalo-Universitaire FIRE, Hôpital Bichat, and Université Paris-Diderot, Sorbonne-Paris Cité (P.G.S.), and Hôpital Européen Georges Pompidou, Assistance Publique-Hôpitaux de Paris, INSERM Unité 970 and Université Paris Descartes (N.D.) — all in Paris; NHLI Imperial College, ICMS, Royal Brompton Hospital, London (P.G.S.); Azienda Ospedaliero-Universitaria di Parma, Parma, Italy (D.A.); Canadian VIGOUR Centre, University of Alberta, Edmonton (P.W.A.) and the Department of Medicine and Population Health Research Institute, McMaster University, Hamilton, ON (E.L.) — both in Canada; Dante Pazzanese Institute of Cardiology (A.A.) and Heart Institute (InCor), University of São Paulo Medical School (J.C.N.) - both in São Paulo; South Australian Health and Medical Research Institute, Flinders University and Medical Centre, Adelaide, SA, Australia (P.E.A.); Cardiogolf/Clinica El Golf, Lima, Perú (A. Bryce); the Department of Cardiology, Peking University People's Hospital, Beijing (H.C.); the Department of Internal Medicine, National Taiwan University Hospital, Taipei, Taiwan (M.-F.C.); Cardiovascular Division Pontificia Universidad Catolica de Chile, Santiago, Chile (R.C.); Milpark Hospital, Johannesburg (A.J.D.); the Department of Cardiology, Academic Medical Center, University of Amsterdam, Amsterdam (R.J.D.W.); Clinic of Cardiology, University Hospital Alexandrovska (S.D.), and the Cardiology Department, Queen Giovanna University Hospital (A.R.G.) — both in Sofia, Bulgaria; ECLA Estudios Cardiológicos Latinoamérica, Rosario, Argentina (R.D.); the Department of Internal Medicine, School of Medicine, University of Ioannina, Ioannina, Greece (M.E.); Norwich Medical School, and Norfolk and Norwich University Hospital — both in Norwich, United Kingdom (M.D.F.); University of Buenos Aires, School of Medicine, Buenos Aires (L.G.); the Department of Medicine, NYU Langone Medical Center, New York (J.S.H.); the Medical Department, Hospital Unit West, Herning/Holstbro, Denmark (S.H.); the Department of Internal Medicine, Seoul National University Hospital, Seoul, South Korea (H.-S.K.); the Department of Internal Medicine II-Cardiology, University of Ulm Medical Center, Ulm, Germany (W.K.); 2nd Department of Medicine, Department of Cardiovascular Medicine, General University Hospital and 1st Faculty of Medicine, Charles University in Prague, Prague, Czech Republic (A.L.); the Department of Cardiology, Hospital Universitario La Paz, IdiPaz, Madrid (J.L.-S.); the Cardiology Department, Asklepeion Hospital, Athens (A.J.M.); University of Pennsylvania, Perelman School of Medicine, Philadelphia (E.R.M.); St. John's Medical Collage, Bangalore, India (P.P.); Institute of Cardiology, Kiev, Ukraine (A.P.); University of Oslo and Oslo University Hospital, Ullevål, Center for Preventive Medicine, Oslo (T.R.P.); 1st Department of Medicine, Faculty of Medicine Pavel Josef Safarik University, Kosice, Slovakia (D.P.); San Jose Satelite Hospital, Naucalpan, 
Mexico (M.A.R.-C.); Russian Cardiologic Research and Production Complex of Rosmedtechnology, Moscow (M.R.); LIFE Health Center, St. George Hospital, Székesfehérvár, Hungary (M.S.); Shaikh Zayed Postgraduate Medical Institute, Lahore, Pakistan (S.S.); the Department of Cardiovascular Medicine, University Hospitals Leuven, Leuven, Belgium (P. Sinnaeve); the Department of Medicine, Faculty of Medicine, Ramathibodi Hospital, Mahidol University, Bangkok, Thailand (P. Sritara); the Department of Cardioresearch, Antonius Hospital, Sneek, the Netherlands (H.P.S.); the Department of Medicine, College of Medicine, University of the Philippines, Manila (R.G.S.); Teikyo Academic Research Center, Itabashi-ku, Tokyo (T.T.); the Cardiology Division, Department of Medicine, Queen Mary Hospital, University of Hong Kong, Hong Kong (H.-F.T.); Henry Ford Heart and Vascular Institute, Detroit (W.D.W.); Maine Research Associates, Auburn (R.W.); Tallinn University of Technology, North Estonia Medical Center, Tallinn, Estonia (M.V.); University of Medicine and Pharmacy, Carol Davila, University and Emergency Hospital, Bucharest, Romania (D.V.); Zhongshan Hospital, Fudan University, Shanghai (J.Z.); and Thrombolysis in Myocardial Infarction Study Group, Brigham and Women's Hospital and Harvard Medical School, Boston (C.P.C.).

\section{REFERENCES}

1. Finn AV, Nakano M, Narula J, Kolodgie FD, Virmani R. Concept of vulnerable/ unstable plaque. Arterioscler Thromb Vasc Biol 2010;30:1282-92.

2. Häkkinen T, Luoma JS, Hiltunen MO, et al. Lipoprotein-associated phospholipase A(2), platelet-activating factor acetylhydrolase, is expressed by macrophages in human and rabbit atherosclerotic lesions. Arterioscler Thromb Vasc Biol 1999; 19:2909-17.

3. Kolodgie FD, Burke AP, Skorija KS, et al. Lipoprotein-associated phospholipase A2 protein expression in the natural progression of human coronary atherosclerosis. Arterioscler Thromb Vasc Biol 2006;26:2523-9.

4. Carpenter KL, Dennis IF, Challis IR, et al. Inhibition of lipoprotein-associated phospholipase A2 diminishes the deathinducing effects of oxidised LDL on human monocyte-macrophages. FEBS Lett 2001;505:357-63.

5. Hsieh CC, Yen MH, Liu HW, Lau YT Lysophosphatidylcholine induces apoptotic and non-apoptotic death in vascular smooth muscle cells: in comparison with oxidized LDL. Atherosclerosis 2000;151: 481-91.

6. MacPhee $\mathrm{CH}$, Moores $\mathrm{KE}$, Boyd HF et al. Lipoprotein-associated phospholipase A2, platelet-activating factor acetylhydrolase, generates two bioactive products during the oxidation of low-density lipoprotein: use of a novel inhibitor. Biochem J 1999;338:479-87.

7. Shi Y, Zhang P, Zhang L, et al. Role of lipoprotein-associated phospholipase A2 in leukocyte activation and inflammatory responses. Atherosclerosis 2007;191:5462.

8. Takahashi M, Okazaki H, Ogata Y, Takeuchi K, Ikeda U, Shimada K. Lysophosphatidylcholine induces apoptosis in human endothelial cells through a p38mitogen-activated protein kinase-dependent mechanism. Atherosclerosis 2002; 161:387-94.
9. Thompson A, Gao P, Orfei L, et al. Lipoprotein-associated phospholipase A(2) and risk of coronary disease, stroke, and mortality: collaborative analysis of 32 prospective studies. Lancet 2010;375:1536-44. 10. Blackie JA, Bloomer JC, Brown MJ, et al. The identification of clinical candidate SB-480848: a potent inhibitor of lipoprotein-associated phospholipase A2. Bioorg Med Chem Lett 2003;13:1067-70.

11. Wilensky RL, Shi Y, Mohler ER III, et al. Inhibition of lipoprotein-associated phospholipase A2 reduces complex coronary atherosclerotic plaque development. Nat Med 2008;14:1059-66.

12. Johnson JL, Shi Y, Snipes R, et al. Effect of darapladib treatment on endarterectomy carotid plaque lipoprotein-associated phospholipase A2 activity: a randomized, controlled trial. PLoS One 2014;9(2):e89034. 13. Serruys PW, García-García HM, Buszman P, et al. Effects of the direct lipoprotein-associated phospholipase $\mathrm{A}(2)$ inhibitor darapladib on human coronary atherosclerotic plaque. Circulation 2008; 118:1172-82.

14. White H, Held C, Stewart R, et al. Study design and rationale for the clinical outcomes of the STABILITY Trial (STabilization of Atherosclerotic plaque By Initiation of darapLadIb TherapY) comparing darapladib versus placebo in patients with coronary heart disease. Am Heart J 2010;160: 655-61.

15. Brosius FC III, Hostetter TH, Kelepouris E, et al. Detection of chronic kidney disease in patients with or at increased risk of cardiovascular disease: a science advisory from the American Heart Association Kidney and Cardiovascular Disease Council, the Councils on High Blood Pressure Research, Cardiovascular Disease in the Young, and Epidemiology and Prevention, and the Quality of Care and Outcomes Research Interdisciplinary Working Group: developed in collaboration with the National Kidney Foundation. Circulation 2006;114:1083-7.
16. Bhatt DL, Steg PG, Ohman EM, et al. International prevalence, recognition, and treatment of cardiovascular risk factors in outpatients with atherothrombosis. JAMA 2006;295:180-9.

17. Bhatt DL, Eagle KA, Ohman EM, et al. Comparative determinants of 4-year cardiovascular event rates in stable outpatients at risk of or with atherothrombosis. JAMA 2010;304:1350-7.

18. Steg PG, Greenlaw N, Tardif JC, et al. Women and men with stable coronary artery disease have similar clinical outcomes: insights from the international prospective CLARIFY registry. Eur Heart J 2012;33:2831-40.

19. O'Donoghue M, Morrow DA, Sabatine MS, et al. Lipoprotein-associated phospholipase A2 and its association with cardiovascular outcomes in patients with acute coronary syndromes in the PROVE IT-TIMI 22 (PRavastatin Or atorVastatin Evaluation and Infection Therapy-Thrombolysis In Myocardial Infarction) trial. Circulation 2006;113:1745-52.

20. Ridker PM, MacFadyen JG, Wolfert RL, Koenig W. Relationship of lipoprotein-associated phospholipase A2 mass and activity with incident vascular events among primary prevention patients allocated to placebo or to statin therapy: an analysis from the JUPITER trial. Clin Chem 2012;58:877-86.

21. Heart Protection Study Collaborative Group. Lipoprotein-associated phospholipase $A_{2}$ activity and mass in relation to vascular disease and nonvascular mortality. J Intern Med 2010;268:348-58.

22. White HD, Simes J, Stewart RA, et al. Changes in lipoprotein-associated phospholipase A2 activity predict coronary events and partly account for the treatment effect of pravastatin: results from the Long-Term Intervention with Pravastatin in Ischemic Disease study. J Am Heart Assoc 2013;2(5):e000360.

Copyright (c) 2014 Massachusetts Medical Society.

RECEIVE IMMEDIATE NOTIFICATION WHEN AN ARTICLE IS PUBLISHED ONLINE FIRST

To be notified by e-mail when Journal articles are published Online First, sign up at NEJM.org. 